OPEN ACCESS

Edited by:

Alisa Rudnitskaya,

University of Aveiro, Portugal

Reviewed by:

Franz Dickert,

University of Vienna, Austria

Mani Govindasamy,

National Taipei University of

Technology, Taiwan

*Correspondence:

Abdellatif Ait Lahcen

abdellatif.aitlahcen@kaust.edu.sa

Khaled Nabil Salama

khaled.salama@kaust.edu.sa

Specialty section:

This article was submitted to

Analytical Chemistry,

a section of the journal

Frontiers in Chemistry

Received: 12 December 2021

Accepted: 18 January 2022

Published: 16 February 2022

Citation:

Beduk T, Gomes $M$

De Oliveira Filho Jl, Shetty SS, Khushaim W, Garcia-Ramirez R,

Durmus $C$, Ait Lahcen A and

Salama KN (2022) A Portable

Molecularly Imprinted Sensor for On-

Site and Wireless Environmental

Bisphenol A Monitoring.

Front. Chem. 10:833899.

doi: 10.3389/fchem.2022.833899

\section{A Portable Molecularly Imprinted Sensor for On-Site and Wireless Environmental Bisphenol A Monitoring}

\author{
Tutku Beduk, Matilde Gomes, José IIton De Oliveira Filho, Saptami Suresh Shetty, \\ Walaa Khushaim, Ricardo Garcia-Ramirez, Ceren Durmus, Abdellatif Ait Lahcen* and \\ Khaled Nabil Salama*
}

Sensors Lab, Advanced Membranes and Porous Materials Center (AMPM), Computer, Electrical and Mathematical Science and Engineering (CEMSE) Division, King Abdullah University of Science and Technology (KAUST), Thuwal, Saudi Arabia

The detection of pollutant traces in the public and environmental waters is essential for safety of the population. Bisphenol A (BPA) is a toxic chemical widely used for the production of food storage containers by plastic industries to increase the storage ability. However, the insertion of BPA in water medium leads to serious health risks. Therefore, the development of low-cost, practical, sensitive, and selective devices to monitor BPA levels on-site in the environment is highly needed. Herein, for the first time, we present a homemade portable potentiostat device integrated to a laser-scribed graphene (LSG) sensor for BPA detection as a practical environmental pollutant monitoring tool. Recently, there has been an increasing need regarding the development of graphenebased electrochemical transducers (e.g., electrodes) to obtain efficient biosensing platforms. LSG platform is combined with molecularly imprinted polymer (MIP) matrix. LSG electrodes were modified with gold nanostructures and PEDOT polymer electrodeposition to create a specific MIP biomimetic receptor for ultrasensitive BPA detection. The sensing device has a Bluetooth connection, wirelessly connected to a smartphone providing high sensitivity and sensitivity (LOD: $3.97 \mathrm{nM}$ in a linear range of .01-10 $\mu \mathrm{M}$ ) toward BPA. Two commercial bottled water samples, tap water, commercial milk, and baby formula samples have been used to validate the reliability of the portable sensor device.

\footnotetext{
Keywords: laser-scribed graphene, electrochemical sensors, molecularly imprinted polymers, bisphenol A, environmental monitoring, KAUSTat
}

\section{INTRODUCTION}

Bisphenol A (BPA) is a well-known chemical and main ingredient for various plastic products in industries, such as epoxy resins, polycarbonate (PC), and PVC plastics, as containers of both food and beverages (Safe, 2000; Im et al., 2016; Santonicola et al., 2019). BPA may also be found in water pipes, dental sealants, food packaging, dyes, and tanning agents (Chen et al., 2016). The chemical structure of BPA deeply resembles and mimics the estradiol structure, a crucial hormone for the reproductive system (Cobellis et al., 2009; Latif et al., 2014; Arul et al., 2021). This leads to a side reaction that keeps BPA in the body as a production of hormones. BPA has been found to decrease the secretion of estradiol and testosterone (Chen et al., 2016). Exposure to BPA has been proven toxic in various age groups worldwide causing crucial health concerns, such as prostate and breast cancer, 
development disabilities, and heart disease (Mielke and GundertRemy, 2009; Pupo et al., 2012). As well as the health effects, BPA has also known as a threat to the environment. The contamination of the water sources, marine, and underground waters, through the propagation of wastewater treatment plants, landfill sites, and industrial effluents have become a huge concern over the past decade. Since most of the environmental pollution consists of plastics and microplastics, BPA is found in freshwater samples (Huang et al., 2012; Campanale et al., 2020). Studies have found that BPA concentrations are higher in highly developed industrial and commercial regions, compared with relatively rural areas (Huang et al., 2012). BPA has also been detected in sediment and sewage sludge. Due to combustion processes, a certain amount of BPA in the air has also been observed (Huang et al., 2012; Vasiljevic and Harner, 2021). Thus, the development of accurate and reliable sensing system for the detection of BPA in industrial fields has great importance in human health and the preservation of the environment.

Different detecting techniques, including electrochemical and analytical methods, have been previously used for BPA detection (Grumetto et al., 2008; Miao et al., 2014; Ghanam et al., 2017; Ben Messaoud et al., 2018; García-Córcoles et al., 2018; Yin et al., 2018; Lee et al., 2019). However, onsite monitoring holds a great importance for environmental sampling (Ali et al., 2020). Electrochemical detection methods provide practicality as well as accuracy and cost effectiveness. In the last decade, the sensor development based on electrochemical sensing strategies has received a high demand due to the high possibility of having flexibility and mobility. Carbonaceous nanostructured materials have provided high compatibility with various chemicals, and these materials have been excessively used for sensor fabrication (Govindasamy et al., 2018; Nehru et al., 2021; Rajaji et al., 2021). Graphene is known for its high mechanical stability, surface area, electrical and thermal conductivity, and mechanical flexibility. Laser-scribed graphene (LSG) electrodes can be produced by scribing on a polyimide sheet with $\mathrm{CO}_{2}$ laser (Lin et al., 2014). LSG electrodes have been previously used for gas sensors, detection of biomolecules, proteins, biomarkers, and neurotransmitters (Fenzl et al., 2017; Ghanam et al., 2020; Lahcen et al., 2020; Beduk et al., 2021a). Electrochemical sensing of BPA requires the use of a working electrode, which is modified by different nanomaterials such as polymers, metal nanoparticles, and/or their combinations (Alam and Deen, 2020; Bas et al., 2021). Molecularly imprinted polymers (MIPs) are synthetic polymers produced via the polymerization of monomers and crosslinkers for the detection of a specific target molecule (Belbruno, 2019; Lahcen and Amine, 2019; Karthika et al., 2021; Xu et al., 2021; Zhang et al., 2021). The combination of molecularly imprinted polymers (MIPs) with LSG electrodes could provide a suitable functionalization platform for sensing applications (Beduk et al., 2020; Marques et al., 2020). MIP-based electrochemical sensors show robustness, high stability, sensitivity, and selectivity due to the specific template fabrication toward the target analyte, providing easy recognition and reusability of the sensing platform (Lahcen et al., 2017). Moreover, the presence of a nanoparticle layer, such as gold nanoparticle (AuNP) modification prior to MIP electrosynthesis, provides a stable electroactive support for EDOT (3,4-ethylenedioxythiophene) polymerization in the presence of a template molecule (Lahcen et al., 2021).

LSGs have been previously demonstrated for BPA detection (Beduk et al., 2020). However, previous reported sensors depend on the use of bulky potentiostats, which is not applicable and practical for on-site applications. Herein, for the first time, all electrochemical measurements were conducted by a portable, custom-made, and wireless potentistat device for on-site environmental monitoring, compared with previous BPA sensors coupled with bulky electrochemical systems. The device consists of a homemade portable potentiostat connected wirelessly to a smartphone and a flexible LSGMIP-based electrochemical sensor. In addition, compared with the previously reported bare polymer matrix on the LSG surface (Beduk et al., 2020), having a gold nanoparticle layer supported by a polymeric matrix serves a highly electroactive role for BPA detection. The practicality of the device allows users to perform on-site detection of BPA in environmental samples with no requirement for sample pretreatment, while the gold combined polymeric matrix provides ultrasensitive BPA detection. The high-quality LSG sensor combined with MIP matrix in gold nanoparticle-polymer matrix provides higher selectivity and sensitivity with an LOD of $3.97 \mathrm{nM}$, compared with the commercial potentiostat device (LOD:15 nM). The sensor surface characteristics, such as morphology, chemical composition, etc., were investigated using physiochemical characterization techniques. The electrochemical performance of the developed sensing device is compared with the commercial potentiostat. Detection performance of the sensing device has been validated by measuring BPA in commercial water, tap water, milk and baby formula samples, as well as the commercial plastic samples with successful recovery rates.

\section{EXPERIMENTAL}

\subsection{Materials and Apparatus}

Polyimide (PI) material with a width size of 12 " was purchased from Utech Products, USA. For buffer preparation, hexaammineruthenium (III) chloride $\left\{\left[\mathrm{Ru}\left(\mathrm{NH}_{3}\right)_{6}\right] \mathrm{Cl}_{3} ; 98 \%\right.$, potassium chloride $(\mathrm{KCl})$, potassium ferrocyanide $\mathrm{K}_{4}$ $\left[\mathrm{Fe}(\mathrm{CN})_{6}\right]$, and potassium ferricyanide $\mathrm{K}_{3}\left[\mathrm{Fe}(\mathrm{CN})_{6}\right]$ were purchased from MP Biomedicals. Phosphate-buffered saline (PBS) tablets were purchased from Fisher Bioreagents. For the solvent preparation, dimethyl sulfoxide $\left[\left(\mathrm{CH}_{3}\right)_{2} \mathrm{SO}\right]$ was purchased from SupraSolv, Merc. Methanol was obtained from VWR company (certified ACS; 99.9\%). Acetic acid (99\%) was purchased from Sigma-Aldrich. Epinephrine $\left(\mathrm{C}_{9} \mathrm{H}_{13} \mathrm{NO}_{3}\right), \beta$ estradiol $\left(\mathrm{C}_{18} \mathrm{H}_{24} \mathrm{O}_{2} ; \geq 98 \%\right)$, 4-chlorophenol $\left(\mathrm{ClC}_{6} \mathrm{H}_{4} \mathrm{OH}\right)$, bisphenol A $\left(\mathrm{C}_{15} \mathrm{H}_{16} \mathrm{O}_{2} ; \geq 99.9 \%\right)$, gold (III) chloride hydrate $\left(\mathrm{HAuCl}_{4}\right)$, 3,4-ethylenedioxythiophene (EDOT; 97\%) hydrochloric acid $(\mathrm{HCl})$, and dibuthyl phthalate $\left(\mathrm{C}_{16} \mathrm{H}_{22} \mathrm{O}_{4}\right.$; $\geq 99 \%$ ) were purchased from Sigma-Aldrich. All other reagents were of analytical grade and used as received without any pretreatment. 


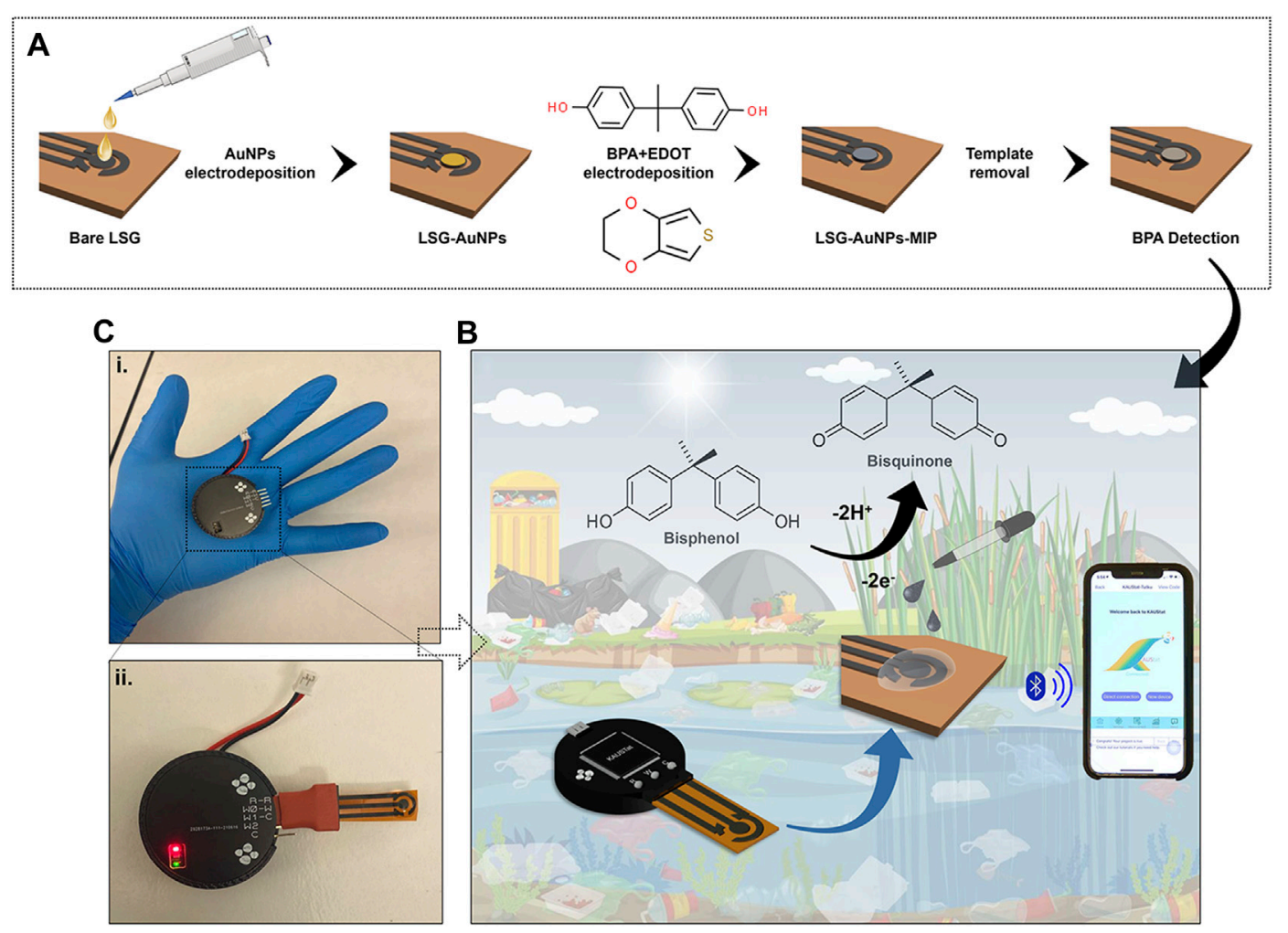

FIGURE 1 | (A) Preparation of the molecular imprinted laser-scribed graphene (LSG) sensor including electropolymerization of gold nanoparticles (AuNPs), 3,4-ethylenedioxythiophene (EDOT) monomer in the presence of bisphenol A (BPA), and template removal to create BPA cavities. (B) Schematic illustration of the portable potentiostat attached to the AuNPs/LSG sensor and connected to a smartphone via Bluetooth for detecting BPA in environmental samples. (C) The pictures of (i) the potentiostat, (ii) the device combined with the LSG-MIP sensor. Red light indicates an active Bluetooth connection.

$\mathrm{A} \mathrm{CO}_{2}$ laser tool (Universal Laser Systems ${ }^{\circledR}$ PLS6.75) was used for laser scribing onto a PI substrate under ambient conditions. The spot diameter and wavelength are fixed as $\sim 150$ and $10.6 \mu \mathrm{m}$, respectively. Prior to the graphene production, necessary optimizations were performed following our previous work, and the DPI was set as a constant to a value of 1,000 to maintain the graphene quality (Beduk et al., 2020). The sensor design was prepared by using the L-Edit software v15.0 from Tanner EDA and uploaded to the laser system. Morphological characterization was done by TENEO VS scanning electron microscope (TENEO VS SEM). The x-ray diffraction data were recorded using an x-ray diffractometer (Bruker Corporation, D8 ADVANCE, and Karlsruhe, Germany) with $\mathrm{Cu} \mathrm{Ka}$ radiation $(1.5406 \AA)$ and $2 \theta$ range of $20^{\circ}-80^{\circ}$. Raman data were obtained at $473 \mathrm{~nm}$ with a cobalt laser source by using a LabRAM ARAMIS Raman spectrometer (Horiba Scientific). Elemental analysis of LSG surfaces was performed by using $\mathrm{x}$-ray photoelectron spectroscopy (XPS) from Kratos Analytical (AMICUS/ESCA 3400) with an Al-Ka X-ray source $(1,468.6 \mathrm{eV})$ applied at $10 \mathrm{kV}$ that generated $10-\mathrm{mA}$ current. Topological imaging and roughness measurements were performed using the Bruker Dimension Icon AFM system. The electrochemical measurements were performed by both our homemade potentiostat device connected to a smartphone and a commercial electrochemical measurement workstation
(Palmsens 4) connected to a computer and controlled by the PSTrace 5.5 software. All experiments were performed in triplicate with LSG reference and counter electrodes at room temperature and at $\mathrm{pH} 7.4$.

\subsection{Preparation of AuNPs Modified LSG-MIP Sensor}

Gold chloroauric acid (50 mM) was prepared in $50 \mathrm{mM} \mathrm{HCl}$ as the precursor solution for gold (AuNPs) electrodeposition. Of the gold solution, $70 \mu \mathrm{l}$ was placed onto the LSG working electrode to perform the chronoamperometry method with respect to the LSG reference and counter electrodes. The current was recorded at a fixed potential value of $-0.9 \mathrm{~V}$ with a time interval of $0.1 \mathrm{~s}$ for 270 s, optimized in our previous work (Rauf et al., 2021). The surface was cleaned and dried with $\mathrm{N}_{2}$ gas following the AuNP electrodeposition. EDOT monomer was electropolymerized on the working electrode (WE) surface in the presence of $1 \mathrm{mM} \mathrm{BPA}$ solution at a fixed potential value of $0.85 \mathrm{~V}$ for $70 \mathrm{~s}$. About $10 \mathrm{mM}$ EDOT was mixed with $1 \mathrm{mM}$ BPA in $50 \mathrm{mM}$ PBS at $\mathrm{pH}$ 7.4. About $10 \mathrm{mM}$ BPA was prepared in dimethyl sulfoxide: $50 \mathrm{mM}$ PBS (3:7, v/v) as the stock solution. Following the adduct step, the attached BPA was removed from the natural cavities on the PEDOT layer by acetic acid:methanol (3:7, v/v) solution for $15 \mathrm{~min}$. The preparation process is schematically described in 
Figure 1A. As the final step, the empty cavities were filled with different concentrations of BPA for the rebinding step. The difference in the current response was observed depending on the occupancy of the BPA-specific cavities on the WE surface.

For reference purposes, the AuNP-/LSG-modified nonimprinted polymer LSG/AuNP-NIP is prepared by the electropolymerization of EDOT in the absence of BPA. Following the AuNP modification on the surface, the EDOT monomer was electropolymerized on the working electrode surface without BPA presence. The same fixed potential value of $0.85 \mathrm{~V}$ and duration were used for the chronoamperometry. EDOT $(10 \mathrm{mM})$ was prepared in $50 \mathrm{mM}$ PBS at $\mathrm{pH} 7.4$.

\subsection{Electrochemical Measurements}

A potential range of -0.6 to $+0.6 \mathrm{~V}$ at a pulse amplitude of $50 \mathrm{mV}$ and a pulse width of $0.1 \mathrm{~s}$ with a scan rate of $100 \mathrm{mV} / \mathrm{s}$ was used to carry out the differential pulse voltammetry (DPV) method by a commercial potentiostat. The same potential range was used to carry out cyclic voltammetry $(\mathrm{CV})$ with a scan rate of $100 \mathrm{mV} / \mathrm{s}$. DPVs by KAUSTat were obtained in the potential range from -0.45 to $+0.45 \mathrm{~V}$ for the rest of the sensing performance investigation.

\subsection{Development of KAUSTat: A Fully Integrated Home-Made Potentiostat}

KAUSTat is a potentiostat device that enables multiple amperometric and voltametric measurement techniques developed in our previous work (Ahmad et al., 2019). Figure 1C shows the handheld potentiostat device connected wirelessly to a smartphone. The device has a Programmable System on Chip (PSoC) 5LP, sensor input/output peripherals, an SD card slot, a Bluetooth module (CYBLE-214015-01), a power management circuit, an RS232-to-USB converter, LEDs, and a micro-USB port for smartphone connection. A customized mobile application software was developed having multiple operation options for connection, parameter, control, and data visualization. The Programmable System on Chip (PSoC) 5LP manages the reconfigurable pins (electrodes) and the internal potentiostat circuitry. Thus, KAUSTat has proven that it has the potential of being an accurate and portable electrochemical detection system, compared with the large-scale commercial electrochemical setups.

\subsection{Real Sample Preparation}

Two different brands of bottled water and tap water samples were selected and spiked with BPA to test the LSG-MIP sensor performance. Each water sample was mixed with $50 \mathrm{mM}$ PBS in $50 \%$ ratio and then was used to prepare 0.1 and $1 \mu \mathrm{M} \mathrm{BPA}$ solutions. Then analyte solutions prepared with water samples were incubated on the sensor for $20 \mathrm{~min}$. Following the water samples, two different brands of plastic bottles were tested with and without spiking. Of the plastic pieces, $2 \mathrm{~g}$ was mixed with $50 \mathrm{ml}$ of deionized water inside a glass container covered by aluminum foil and kept on a hot plate at $70^{\circ} \mathrm{C}$ for $16 \mathrm{~h}$. After the solutions were cooled, $5 \mathrm{ml}$ of each plastic solution was mixed with $5 \mathrm{ml}$ of $50 \mathrm{mM}$ PBS to incubate for $20 \mathrm{~min}$ at the rebinding step. In addition to directly measuring plastic solutions, they were also spiked with 0.1 and $1 \mu \mathrm{M}$ BPA to observe the current change at different concentrations of BPA. Finally, two different bottled milk samples and a local brand of baby formula solution was spiked with 0.1 and $1 \mu \mathrm{M}$ BPA and tested. Of each sample, $5 \mathrm{ml}$ was mixed with $5 \mathrm{ml}$ of $50 \mathrm{mM}$ PBS to prepare the BPA solutions for incubation onto the sensor.

\section{RESULTS AND DISCUSSION}

\subsection{Design of the Portable Potentiostat Device}

A reconfigurable potenstiostat called KAUSTat was designed inhouse to conduct sensing measurements on-site. The device presents a proof of concept for in-field deployment of our sensor. KAUSTat is suitable for reprogramming of the internal circuitry according to the requirements of a specific application. Similar to an FPGA (field-programmable gate array), a design was created and deployed into the KAUSTat core. The main circuitry consists of a 32-bit Arm ${ }^{\circledR}$ Cortex $^{\circledR}$-M3 programmable system on chip (PSoC), a Bluetooth module (CYBLE-214015-01) and a $3.7-\mathrm{V}, 70-\mathrm{mA} / \mathrm{h}$ lithium battery. This design consists of a standard potentiostat circuitry having three electrodes and embodies a delta-sigma analog-to-digital converter ( $\Delta \sum$-ADC), two digital-to-analog converters (DAC), and two operational amplifiers with programmable feedback resistance. The device can also change its impedance to control the current flow into the electrode. This circuitry modification happens directly in the operational amplifier and feedback resistance, complementary to the voltage potential applied into the electrodes. The optimization of the device including the impedance effect was investigated in our previous work (Beduk et al., 2021b). Two multiplexes were added to the system to allow the potential of the sensor readout change from three- to two-electrode cells. The side and top views of the device are presented in Supplementary Figure S1. The total diameter and the height of the device were measured as 4 and $1.5 \mathrm{~cm}$, respectively. The device weighs $20 \mathrm{~g}$ with the battery and case. A user-friendly mobile application was developed to control the electrochemical techniques applied by KAUSTat. Multiple windows are available at the interface for control, method selection, operation, and data visualization, shown in Supplementary Figure S2. The communication between the smartphone and KAUSTat is made possible through the Generic Attribute Profile (GATT) Bluetooth protocol. Universal asynchronous receiver/transmitter (UART) was established to communicate with the PSoC. Figure 2 shows the block diagram of the peripherals and circuitry of the device.

\subsection{Characterization of LSG-MIP and LSG-NIP Sensor}

The representative SEM images in Figure 3A show the difference in structure for bare LSG, AuNP/LSG, LSG-NIP, and LSG-MIP. The gold nanoparticle flakes are clearly observed in alignment of our previous work (Rauf et al., 2021). Following the EDOT polymerization, the LSG flakes were observed as covered by 

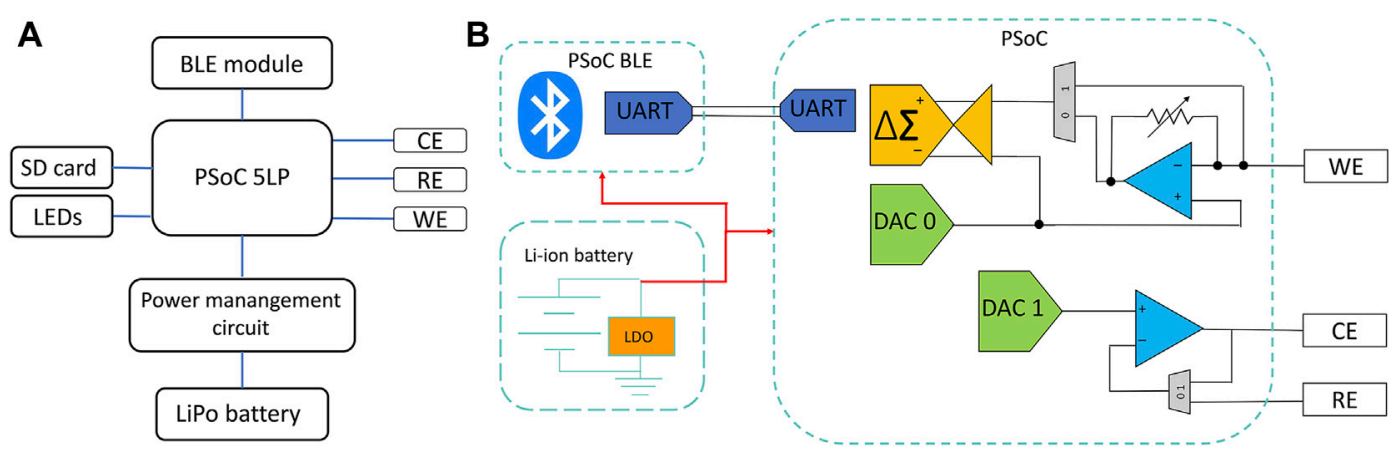

FIGURE 2 | (A) Block diagram of the device components. (B) Potentiostat circuitry implemented in KAUSTat.
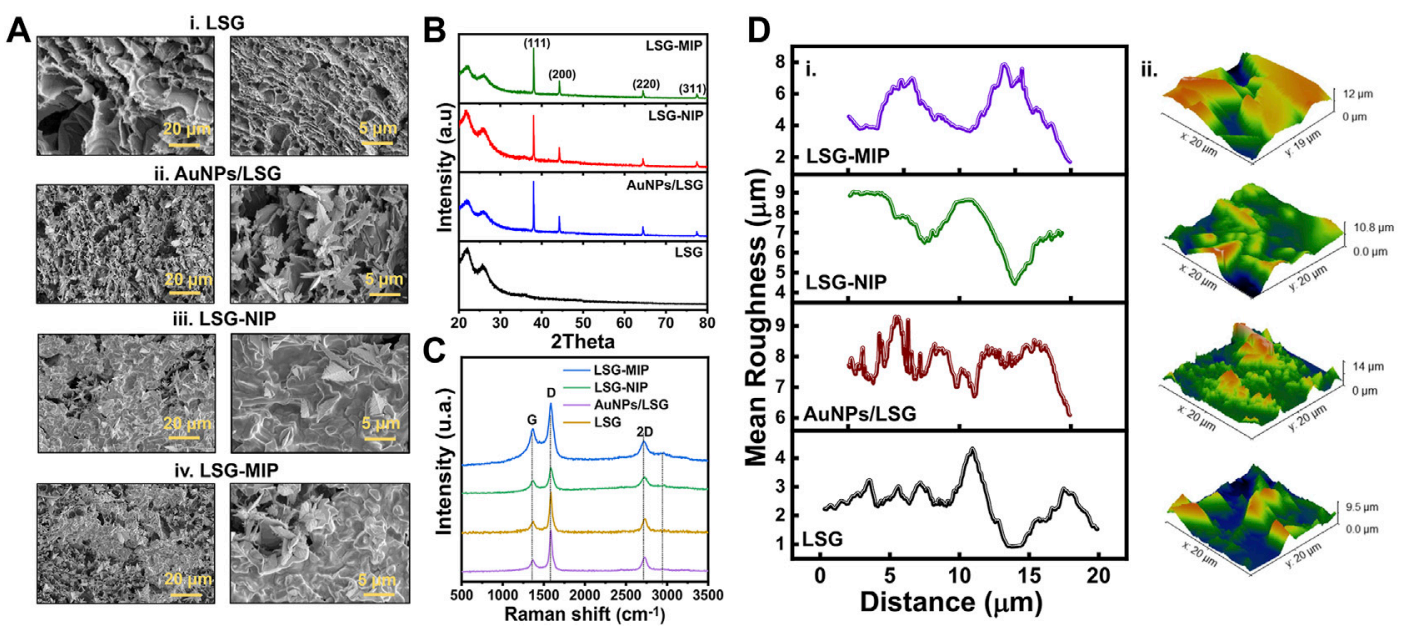

FIGURE 3 | (A) SEM images with scale bars of 20 and $5 \mu \mathrm{m}$, (B) XRD spectra, (C) Raman spectra, and (D) AFM mean roughness measurements and 3D topology images of (i) bare LSG, (ii) LSG/AuNPS, (iii) LSG-NIP (LSG-AuNP-PEDOT), (iv). LSG-molecularly imprinted polymer (MIP) (LSG-AuNP-PEDOT-BPA) sensor.

the PEDOT layer. The gold flakes are embedded in the polymer matrix in LSG-NIP and LSG-MIP samples. Results were supported by EDX analysis shown in Supplementary Figure S3 including mapping. The presence of carbon, oxygen, nitrogen and sulfur was confirmed after the deposition of the PEDOT layer. In addition to qualitatively identifying the elements in each sample, XPS analysis was conducted for each sample. The highresolution spectra of each sample are displayed in Supplementary Figure S4. The C 1s high-resolution spectrum shows the characteristic peaks of the $\mathrm{C}=\mathrm{C}$ bonds of graphene. In addition, the peaks located at 85.3 and $89.9 \mathrm{eV}$ were the characteristic peaks of $\mathrm{Au} 4 \mathrm{f}_{7 / 2}$ and $\mathrm{Au} 4 \mathrm{f}_{5 / 2}$ belonging to the AuNPs electrodeposited onto graphene. Following EDOT polymerization, $\mathrm{N}-\mathrm{C}\left(\mathrm{sp}^{3}\right)$ bonding occurs on the surface, visible in $\mathrm{N}$ 1s high-resolution spectra (Vusa et al., 2017). Broad peaks of $S 2 p$ spectrum and relatively sharp peaks of $\mathrm{C} 1 \mathrm{~s}$ spectrum represent $\mathrm{S} 2 \mathrm{p}_{1 / 2}$ and $\mathrm{C}-\mathrm{C}, \mathrm{C}-\mathrm{S}, \mathrm{C}-\mathrm{O}-\mathrm{C}, \mathrm{C}=\mathrm{O}$ bondings, respectively (Saxena et al., 2011; Abas et al., 2019). Supplementary Table S1 has mass percentage values of LSG, AuNP/LSG, LSG-MIP, and LSG-MIP sensor surface. This quantitative analysis proved the presence of $\mathrm{N} 1 \mathrm{~s}, \mathrm{~S} 2 \mathrm{p}$, as well as the increase in $\mathrm{C} 1 \mathrm{~s}, \mathrm{O}$ 1s composition in NIP and MIP samples. The surface of the LSG-NIP electrode is observed as having the highest composition of $\mathrm{S}$, proving the PEDOT polymer layer coverage.

In contrast, the LSG-MIP surface, having both PEDOT layer and BPA-filled cavities created in the polymer matrix, exhibits lower $\mathrm{S}$ and higher $\mathrm{C}, \mathrm{O}$ composition. In addition to elemental characterization, crystallinity of the sensor surface was investigated. XRD spectra in Figure 3B indicates two clear peaks at $2 \theta=\sim 21.3^{\circ}$ and $\sim 25.6^{\circ}$, indicating the (002) plane coming from the high degree of graphitization (Beduk et al., 2020). After gold electrodeposition, the XRD spectrum exhibited a high degree of crystallinity at $38.01^{\circ}\left(\begin{array}{lll}1 & 1 & 1\end{array}\right), 44.18^{\circ}\left(\begin{array}{lll}2 & 0 & 0\end{array}\right)$,

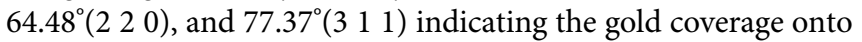
the LSG surface, matching with the ICSD reference code of 96900-8464 (Krishnamurthy et al., 2014). Further polymer modification onto the gold surface does not affect the crystallinity as observed in Figure 3B. The Raman spectra in Figure $3 \mathrm{C}$ shows the highest I2D/IG peak intensity ratio in bare 

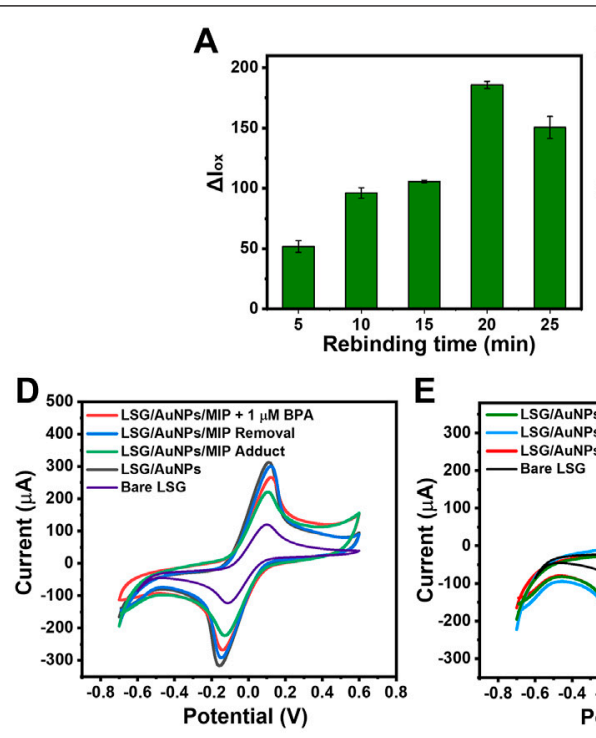

E
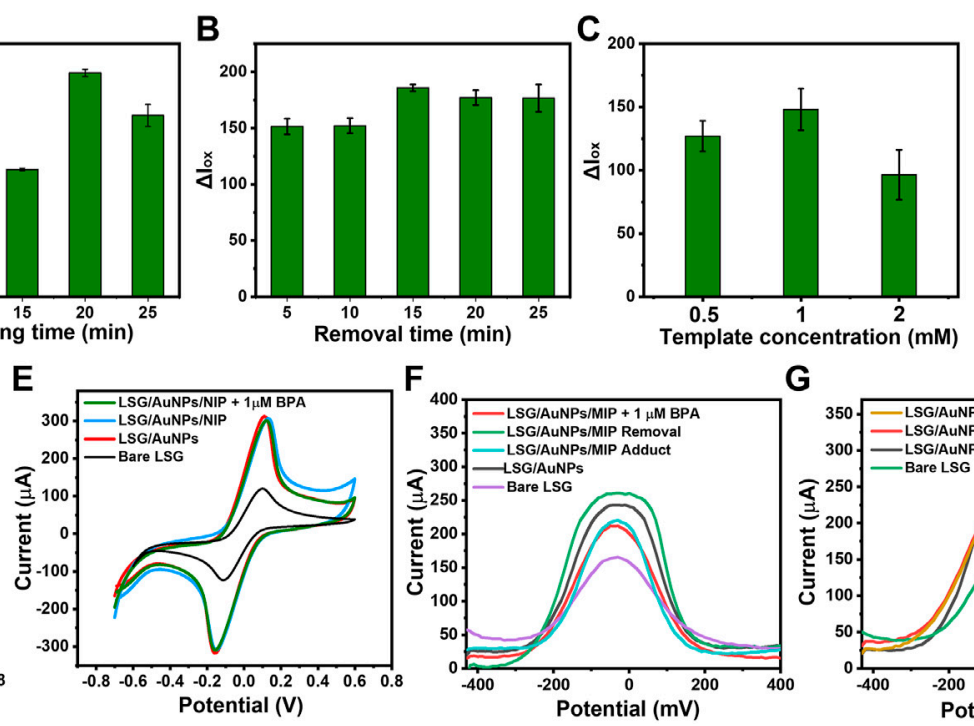

G

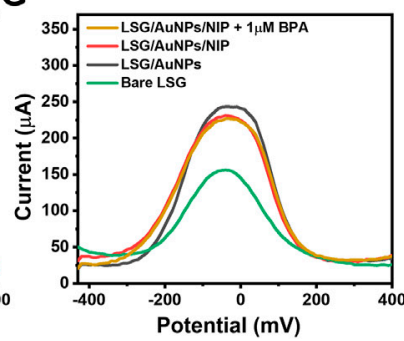

FIGURE 4 | Histograms showing the oxidation current difference before and after rebinding BPA ( $\triangle$ lox) obtained from differential pulse voltammetries (DPVs) of LSG-MIP for (A) rebinding time optimization after binding $1 \mu \mathrm{M}$ BPA of different rebinding times, (B) removal time optimization using 20-min rebinding time for $1 \mu \mathrm{M}$ BPA, (C) template concentration optimization using $15 \mathrm{~min}$ of removal time and $20 \mathrm{~min}$ of rebinding time for $1 \mu \mathrm{M}$ BPA. Cyclic voltammetries (CVs) of (D) LSG-MIP and (E) LSG-NIP in a solution of $5 \mathrm{mM}\left[\mathrm{Fe}(\mathrm{CN})_{6}\right]^{3-/ 4-}$ with $0.1 \mathrm{M} \mathrm{KCl}$ (scan rate: $100 \mathrm{mV} / \mathrm{s}$ ) performed by Palmsens showing the oxidation response of bare LSG, LSG/ AuNP, before and after rebinding of $1 \mu \mathrm{M}$ BPA. DPVs of (D) LSG-MIP and (E) LSG-NIP in a solution of $5 \mathrm{mM}\left[\mathrm{Fe}(\mathrm{CN})_{6}\right]^{3-/ 4-}$ with $0.1 \mathrm{M} \mathrm{KCl}$ performed by KAUSTat showing the oxidation response of bare LSG, AuNPs/LSG, before and after rebinding of $1 \mu \mathrm{M}$ BPA.

LSG correlating with the presence of graphene. The mean roughness profiles of the working electrode surface are presented in Figure 3D for LSG, AuNP/LSG, LSG-NIP, and LSG-MIP. 3D AFM images of samples shows that LSG surface roughness increases after the gold deposition. Following the polymer deposition, surface height significantly increases due to the relatively tick polymer matrix forming on the surface.

\subsection{Optimization of Experimental Conditions}

Molecular imprinting was performed by electrodepositing EDOT on the surface of the AuNP/LSG. The electrodeposition process took place in the presence of a certain amount of BPA as the template molecule. When the specific cavities formed on the polymer matrix, BPA was removed from the surface. These empty $\mathrm{BPA}$ cavities later bind selectively to BPA molecules within a solution, causing an oxidation current difference in electrochemical signal. The polymer layer having embedded BPA cavities interacts with the LSG surface by the hydrogen bonding and the $\pi$ stacking interactions (Zheng et al., 2018). Prior to electrochemical characterization, we performed optimization for the experimental steps. Rebinding and removal time was optimized by using $1 \mathrm{mM}$ BPA template concentration with a $50 \mathrm{mM}$ EDOT solution. A drop in current response was observed after 20 min of rebinding BPA. This might be due to the over blockage of the current by a high amount of analytes accumulating on the surface. In addition, the removal duration was optimized by removing the template from 5 to $25 \mathrm{~min}$. No significant current change was observed after $15 \mathrm{~min}$ of removal time. Therefore, these values were chosen as the optimum, shown in Figures 4A, B. As the final step, template concentration was optimized by keeping $15 \mathrm{~min}$ of removal and $20 \mathrm{~min}$ of rebinding time constant. Among the three concentrations shown in Figure 4C, the highest oxidation current was obtained from the sensor prepared with $1 \mathrm{mM} B P A$ as the template concentration.

$\mathrm{CV}$ results in Figures 4D, E represent the electrochemical characterization performed by a commercial potentiostat. MIP formation, successful removal, and rebinding of the template were observed compared with NIP. DPV response of LSG-MIP and LSG-NIP obtained by KAUSTat is given in Figures 4F, G. Following the gold electrodeposition, a current increase was observed due to the high conductivity and large surface area accelerating the electron transfer. When the EDOT monomer polymerized on the surface to create the MIP matrix, the current decreased due to the presence of the template molecule. Removal procedure empties the BPA cavities eventually leading to a high electroactive area and current intensity. The empty cavities are actively filled once a BPA solution was introduced to the sensor causing a current decrease depending on the analyte concentration. The current responses obtained from both commercial potentiostat and KAUSTat follow the same trend allowing the identification of the BPA concentration by the LSGMIP sensor. However, the LSG-NIP sensor cannot detect BPA in any concentration due to the absence of analyte-specific cavities.

To investigate the template recognition ability more precisely, the imprinting factor was calculated from the oxidation current responses of the LSG-MIP and LSG-NIP using the following equation:

$$
\alpha=\Delta I \text { ox }(L S G-M I P) / \Delta I \text { ox }(L S G-N I P)
$$



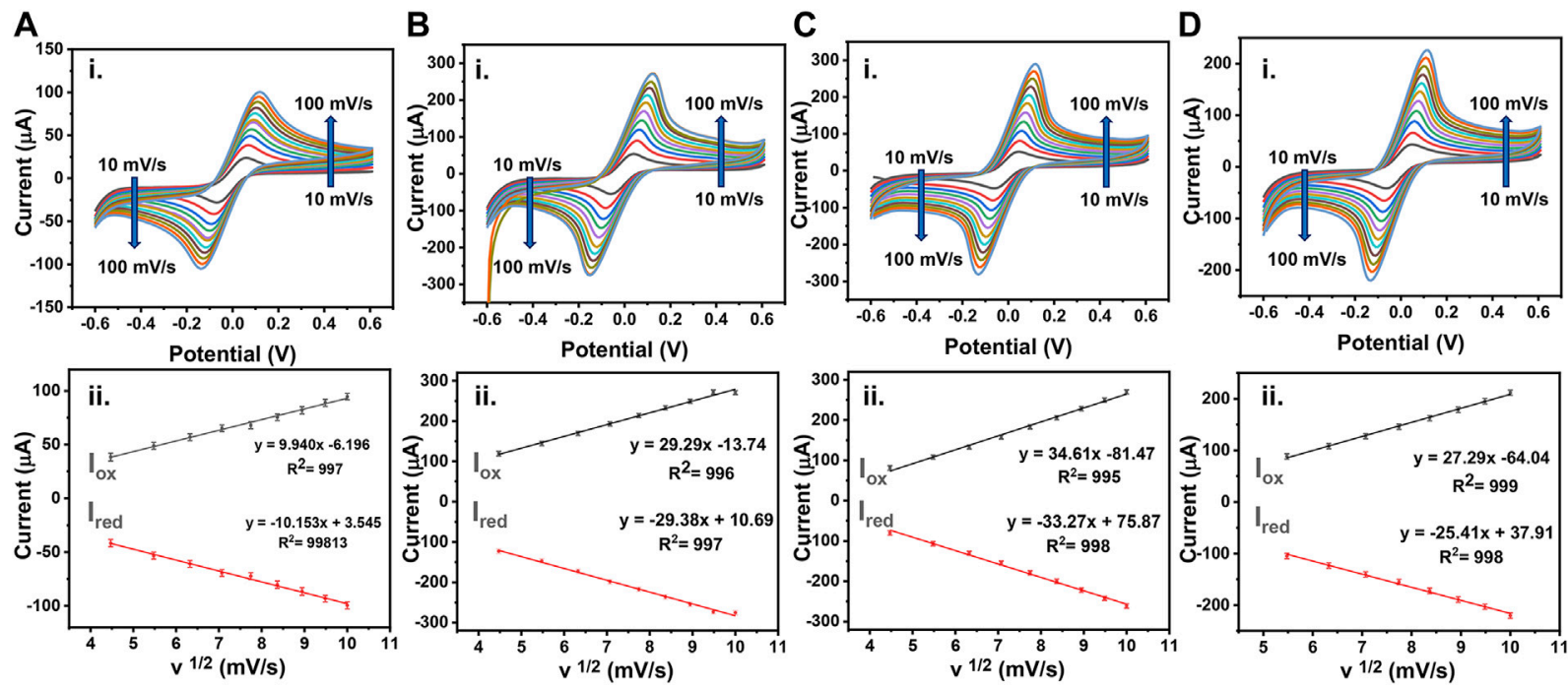

FIGURE 5 | (i) CVs obtained using $0.1 \mathrm{M} \mathrm{KCl}$ containing $5 \mathrm{mM}\left[\mathrm{Fe}(\mathrm{CN})_{6}\right]^{3-/ 4-}$ as a redox probe or (A) bare LSG, (B) AuNPS/LSG, (C) LSG-NIP, (D) LSG-MIP different scan rates from 0.1 to 1 V/s. (ii) The plots show I vs. V $^{1 / 2}(\mathrm{mV} / \mathrm{s})$ for (A) bare LSG, (B) AuNPs/LSG, (C) LSG-NIP, (D) LSG-MIP sensor.

where $\alpha$ is the imprinting factor, $\Delta \mathrm{I}$ ox (LSG-MIP) is the oxidation current difference occurring at the LSG-MIP sensor in the presence of $1 \mu \mathrm{M}$ of BPA, and $\Delta \mathrm{I}$ ox (LSG-NIP) is the oxidation current difference occurring at the LSG-NIP sensor in the presence of $1 \mu \mathrm{M}$ of $\mathrm{BPA}$. The imprinting factor refers to the oxidation response value of the LSG-MIP surface compared with the response value of LSG-NIP to the presence of the same amount of BPA. The imprinting factor was calculated as 9.6, supporting the fact that LSG-MIP has a significantly high absorption capacity toward the specific analyte.

\subsection{Electrochemical Activity of Bisphenol A on Molecularly Imprinted Polymer Sensor}

The voltametric sweeping was performed for bare LSG electrode, AuNP/LSG, LSG-NIP, and LSG-MIP electrodes in the potential range from -0.6 to $0.6 \mathrm{~V}$. The oxidation and reduction current intensities were recorded at scan rates between 10 and $1 \mathrm{mV} / \mathrm{s}$ with respect to bare LSG reference and counter electrodes, shown in Figure 5. The electrochemically active surface area of the sensors was calculated by using the equation below following the Randles-Sevick equation:

$$
I \mathrm{pa}=268600 n^{\wedge}(3 / 2) A D^{\wedge}(0.5) C v^{\wedge}(0.5)
$$

where $D$ is the diffusion coefficient $\left(6.70 \times 10^{-6} \mathrm{~cm}^{2} \mathrm{~s}^{-1}\right), A$ is the active surface area of the electrode, $C$ is the concentration of the redox probe $\left(\mathrm{mol} \cdot \mathrm{cm}^{-3}\right), v$ is the scan rate $\left(\mathrm{mV} \mathrm{s}^{-1}\right)$, and $I_{\mathrm{p}}$ is the anodic peak current (A). A high conductivity of AuNPs/LSG leads to a higher active surface area $\left(0.143 \mathrm{~cm}^{2}\right)$ compared with a bare LSG working electrode $\left(0.080 \mathrm{~cm}^{2}\right)$. The redox current values are recorded for AuNP/LSG compared with the bare LSG in redox probe solutions. Supplementary Table S2 summarizes the anodic and cathodic peak values in both $[\mathrm{Ru}$ $\left.\left(\mathrm{NH}_{3}\right)_{6}\right]^{3+}$ and $\left[\mathrm{Fe}(\mathrm{CN})_{6}\right]^{3-}$. The variations between measurements are small and provide a repeatable reaction, having enhanced $I_{\mathrm{pa}}$ and $I_{\mathrm{pc}}$ values for metal-deposited LSG surface. Figures 5C, D represent the CV response of LSG-MIP and LSG-NIP recorded in $\left[\mathrm{Fe}(\mathrm{CN})_{6}\right]^{3 / 4-}$ redox probe at the potential range from -0.6 to $0.6 \mathrm{~V}$, respectively. The gold surface was modified with the PEDOT layer in the presence of the template analyte leading to a decrease in electroactivity and an active surface area value of $0.127 \mathrm{~cm}^{2}$. On the other hand, the LSG-NIP sensor leads to a higher active surface area $\left(0.162 \mathrm{~cm}^{2}\right)$ due to the absence of any template. Equations of corresponding oxidation and reduction CVs are given in Supplementary Table S3. A linear behavior for $I_{\mathrm{p}}$ vs. the square root of $v$ is obtained for each sensor, which indicates a diffusion-controlled charge transfer.

\subsection{Sensing Performance of Molecularly Imprinted Polymer Sensor}

The oxidation current response of the LSG-MIP sensor was recorded after rebinding different concentrations of BPA by the portable KAUSTat device. The calibration curve on Figure 6B shows a direct relation between the current response and $\log \mathrm{C}_{\mathrm{BPA}}$. High concentrations of the analyte occupy the electroactive imprinted cavities more, leading to a poor conductivity on the surface. The equation obtained from the calibration curve was $\Delta \mathrm{I}(\mu \mathrm{A})=50.6 \log \mathrm{C}_{\mathrm{BPA}}-12.61(\mathrm{R}=0.997)$. The detection limit (LOD) was calculated as $3.97 \mathrm{nM}$ from a linear range of $0.01-10 \mu \mathrm{M}(\mathrm{LOD}=3 \sigma / \mathrm{S}, \mathrm{S} / \mathrm{N}=3)$. In addition to KAUSTat, a commercial potentiostat was also used to validate the performance of the LSG-MIP sensor. The LOD value was calculated as $15 \mathrm{nM}$ in the range of $0.01-10 \mu \mathrm{M}$ from the calibration equation of $\Delta \mathrm{I}(\mu \mathrm{A})=47.1 \log \mathrm{C}_{\mathrm{BPA}}+26.31$ 

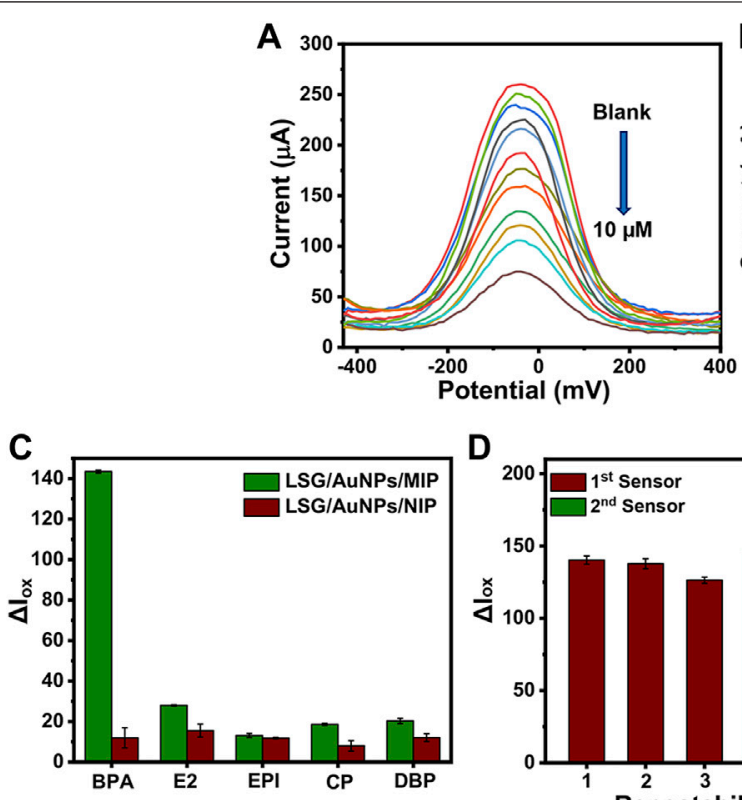

D
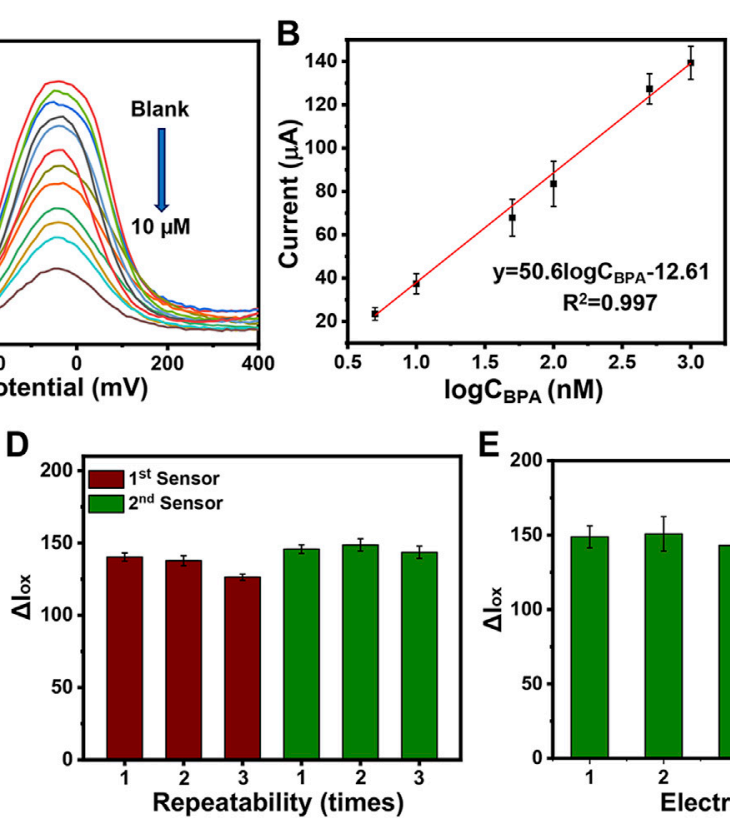

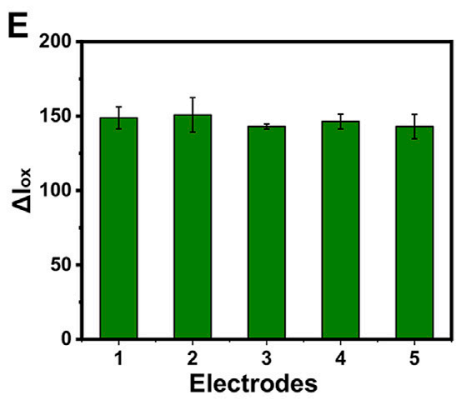

FIGURE 6 | (A) DPVs obtained at LSG-MIP incubated in different concentrations of BPA. (B) The corresponding calibration plot obtained for LSG-MIP. Histograms obtained from lox values of (C) LSG-MIP and LSG-NIP in the presence of BPA, epinephrine (EPI), $\beta$-estradiol (E2), 4-chlorophenol (CP), and dibutyl phthalate (DBP). The concentration of BPA and other inferences used was $1 \mu \mathrm{M}$, (D) LSG-MIP showing the reusability of two different sensors performing removal and rebinding three times consecutively. (E) Reproducibility test showing the response of five different LSG-MIP sensors prepared with the same procedure. The measurements were done by using optimal conditions ( $1 \mathrm{mM} \mathrm{BPA}, .5 \mathrm{M} \mathrm{EDOT}, 15 \mathrm{~min}$ of removal time, and 20 min of incubation time of $1 \mu \mathrm{M}$ of $\mathrm{BPA}) . \mathrm{KCl}(0.1 \mathrm{M}) \mathrm{containing} 5 \mathrm{mM}\left[\mathrm{Fe}(\mathrm{CN})_{6}\right]^{3-/ 4-}$ was used as the redox probe.

$\left(\mathrm{R}^{2}=0.997\right)$, shown in Supplementary Figure S5. Since the enhanced sensitivity was obtained by the portable potentiostat device, the rest of the sensing performance tests were conducted by KAUSTat. In another sensing performance test, selectivity was tested by recording the electrochemical responses of the other interferences by KAUSTat having structural similarities with the main analyte, estradiol, epinephrine, dibutyl phthalate, and 4chlorophenol examined by the same procedure with the previously optimized parameters for BPA. The LSG-MIP sensor responded slightly to $1 \mu \mathrm{M}$ of the interferences shown in Figure 6C. However, an approximately fourfold increase was observed in the response of BPA compared with the current response of interferences, confirming the high affinity of the LSGMIP sensor toward BPA. On the other hand, the LSG-NIP sensor did not particularly show a significant result for any of the compounds including BPA due to the lack of cavities and specific binding. The high selectivity is due to the imprinted polymeric matrix specifically designed and optimized for the BPA molecule. The conditions of MIP synthesis, such as selection of appropriate functional monomer, removal time and agent, and incubation time were optimized among various parameters, resulting in a customized synthesis method for MIP toward the detection of BPA on an LSG sensor.

The possibility of reperforming the removal procedure for the same sample was investigated to understand the reusability of the same sensor. Figure 6D shows the oxidation current responses of two different sensors with three removal-rebinding cycles. After every cycle, the sensor response is slightly reduced. Finally, the
$10 \%$ of the initial sensor response faded after three removal-rebinding cycles. This current loss can be explained by the slight damage coming from using an acetic acid/methanol (3:7) mixture as the removal solution to remove BPA from the previously created cavities. In addition, Figure $6 \mathrm{E}$ shows the current responses coming from five different LSG-MIP sensors prepared by the exact same method. Having approximately $94.8 \%$ of the same current value stable for each electrode as the response to $1 \mu \mathrm{M}$ BPA explains that the proposed imprinting method provides a stable alternative to the existing BPA sensors in the market.

\subsection{Determination of Bisphenol A in Real Samples}

The verification of the LSG-MIP sensor performance was performed by using real samples shown in Table 1. Two local brands of bottled water and milk samples, tap water, and a local brand of baby formula solution were spiked with a known amount of BPA to obtain recovery values. By spiking samples by 0.01 and $1 \mu \mathrm{M}$ BPA, calculated RSD (\%) values are observed as varying between $82.84 \%$ and $120.2 \%$. In addition to the liquid samples, two local brands of bottled water were used to detect BPA. Following a consistence heating procedure, the initial concentration of BPA was detected along with the recovery values of the spiked amounts. Recovery values ranging between $97.27 \%$ and $112.2 \%$ proves the successful detection of BPA at varying concentrations in real samples. 
TABLE 1 | Determination of BPA in water, milk and plastic samples by LSG-MIP sensor.

\begin{tabular}{|c|c|c|c|c|c|c|c|c|c|c|}
\hline & \multicolumn{5}{|c|}{ Commercial potentiostat } & \multicolumn{5}{|c|}{ KAUSTat } \\
\hline & $\begin{array}{c}\text { Initial } \\
\text { concentration } \\
\text { (nM) }\end{array}$ & $\begin{array}{c}\text { Added } \\
\text { (nM) }\end{array}$ & $\begin{array}{c}\text { Found } \\
\text { (nM) }\end{array}$ & $\begin{array}{c}\text { Recovery } \\
(\%)\end{array}$ & RSD & $\begin{array}{c}\text { Initial } \\
\text { concentration } \\
\text { (nM) }\end{array}$ & $\begin{array}{c}\text { Added } \\
\text { (nM) }\end{array}$ & $\begin{array}{c}\text { Found } \\
\text { (nM) }\end{array}$ & $\begin{array}{c}\text { Recovery } \\
\text { (\%) }\end{array}$ & RSD \\
\hline \multirow{2}{*}{$\begin{array}{l}\text { Water } \\
\text { sample } 1\end{array}$} & 0 & 10 & 8.695 & 86.95 & 9.88 & 0 & 10 & 12.024 & 120.2 & 1.23 \\
\hline & 0 & 1,000 & 1179.3 & 117.9 & 3.12 & 0 & 1,000 & 828.42 & 82.84 & 3.69 \\
\hline \multirow{2}{*}{$\begin{array}{l}\text { Water } \\
\text { sample } 2\end{array}$} & 0 & 10 & 15.917 & 159.2 & 9.87 & 0 & 10 & 10.417 & 104.174699 & 8.68 \\
\hline & 0 & 1,000 & 939.69 & 93.96 & 1.81 & 0 & 1,000 & $1,093.1$ & 109.3 & .68 \\
\hline \multirow[t]{2}{*}{ Tap water } & 0 & 10 & 7.667 & 76.67 & 4.04 & 0 & 10 & 9.339 & 93.39 & 8.87 \\
\hline & 0 & 1,000 & 983.03 & 98.30 & 9.88 & 0 & 1,000 & 1,069.6 & 106.9 & 1.06 \\
\hline \multirow{2}{*}{$\begin{array}{l}\text { Milk } \\
\text { sample } 1\end{array}$} & 0 & 10 & 11.059 & 110.6 & 1.99 & 0 & 10 & 9.1967 & 91.97 & 8.79 \\
\hline & 0 & 1,000 & 941.05 & 94.11 & 3.93 & 0 & 1,000 & $1,092.8$ & 109.3 & 1.98 \\
\hline \multirow{2}{*}{$\begin{array}{l}\text { Milk } \\
\text { sample } 2\end{array}$} & 0 & 10 & 14.114 & 141.1 & 3.85 & 0 & 10 & 11.08 & 110.8 & 3.45 \\
\hline & 0 & 1,000 & 799.73 & 79.97 & 8.04 & 0 & 1,000 & $1,034.7$ & 103.4 & 1.98 \\
\hline \multirow{2}{*}{$\begin{array}{l}\text { Baby } \\
\text { formula }\end{array}$} & 0 & 10 & 10.616 & 106.2 & 3.83 & 0 & 10 & 11.701 & 117.0 & 6.26 \\
\hline & 0 & 1,000 & 1,029.9 & 102.9 & 4.31 & 0 & 1,000 & 1,057.9 & 105.8 & 6.23 \\
\hline \multirow{2}{*}{$\begin{array}{l}\text { Plastic } \\
\text { bottle } 1\end{array}$} & 344.45 & 100 & 397.12 & 86.26 & 1.45 & 119.43 & 100 & 126.2 & 105.7 & 1.78 \\
\hline & 344.45 & 1,000 & 1,348.1 & 106.5 & 3.36 & 133.23 & 1,000 & 1,134.0 & 112.2 & 5.41 \\
\hline \multirow{2}{*}{$\begin{array}{l}\text { Plastic } \\
\text { bottle } 2\end{array}$} & 302.44 & 100 & 421.97 & 101.1 & 0.48 & 119.43 & 100 & 140.13 & 97.27 & 0.79 \\
\hline & 302.44 & 1,000 & 1,311.8 & 103.1 & 3.54 & 133.2 & 1,000 & 1,129.6 & 105.2 & 6.31 \\
\hline
\end{tabular}

\section{CONCLUSION}

Custom-made LSG-MIP sensors were manufactured using standard laser irradiation and electrodeposition method to create a synthetic receptor matrix. Having AuNPs coupled with the PEDOT matrix enhances the stability of the platform and the sensitivity toward BPA in terms of the electrochemical response. The formation of the electrodeposited layers was corroborated by morphological and elemental characterization methods. The electrochemical performance and the active surface area of the developed sensor were characterized by cyclic voltammetry using both $\left[\mathrm{Fe}(\mathrm{CN})_{6}\right]^{3-}$ and $\left[\mathrm{Ru}\left(\mathrm{NH}_{3}\right)_{6}\right]^{3+}$ redox probes. The electrochemically active surface area was found to be $30 \%$ lower for LSG-MIP compared with LSG-NIP due to the occupation of the cavities with the template molecule. The developed sensor was combined with a portable potentiostat connected to a smartphone via Bluetooth. Having a customized smartphone app, our homemade potentiostat does not require any particular training to operate and is fully applicable to on-site pollutant detection without the need of any bulky detection system. In this study, the practicality allows users to monitor BPA existence in environmental samples on-site. This customized device exhibited relatively higher selectivity and sensitivity (LOD: $3.97 \mathrm{nM}$ ) compared with laboratory-based potentiostat systems, proving its great prominent potential as an electrochemical transducer for chemical and bioassays. This new sensing platform could be easily extended to monitor the levels of other endocrines disrupting chemicals in complicated matrices.

\section{DATA AVAILABILITY STATEMENT}

The original contributions presented in the study are included in the article/Supplementary Material, Further inquiries can be directed to the corresponding authors.

\section{AUTHOR CONTRIBUTIONS}

KS and AL conceived and conceptualized the study, KS provided the resources, and acquired funding. MG, TB, RG-R, SS, and CD performed the characterization and electrochemical measurements. JF developed the potentiostat device wrote the software for the PoC measurements. TB wrote the manuscript, with the supervision of $\mathrm{AL}$ and $\mathrm{KS}$.

\section{ACKNOWLEDGMENTS}

The authors would like to express their acknowledgment to the financial support of funding from the King Abdullah University of Science and Technology (KAUST), Saudi Arabia.

\section{SUPPLEMENTARY MATERIAL}

The Supplementary Material for this article can be found online at: https://www.frontiersin.org/articles/10.3389/fchem.2022.833899/ full\#supplementary-material 


\section{REFERENCES}

Abas, A., Sheng, H., Ma, Y., Zhang, X., Wei, Y., Su, Q., et al. (2019). PEDOT:PSS Coated $\mathrm{CuO}$ Nanowire Arrays Grown on $\mathrm{Cu}$ Foam for High-Performance Supercapacitor Electrodes. J. Mater. Sci. Mater. Electron. 30, 10953-10960. doi:10.1007/s10854-019-01469-9

Ahmad, R., Surya, S. G., Sales, J. B., Mkaouar, H., Catunda, S. Y. C., Belfort, D. R., et al. (2019). KAUSTat: A Wireless, Wearable, Open-Source Potentiostat for Electrochemical Measurements. IEEE SENSORS: IEEE, 1-4.

Alam, A. U., and Deen, M. J. (2020). Bisphenol A Electrochemical Sensor Using Graphene Oxide and $\beta$-Cyclodextrin-Functionalized Multi-Walled Carbon Nanotubes. Anal. Chem. 92, 5532-5539. doi:10.1021/acs.analchem. 0c00402

Ali, M. Y., Alam, A. U., and Howlader, M. M. R. (2020). Fabrication of Highly Sensitive Bisphenol A Electrochemical Sensor Amplified with Chemically Modified Multiwall Carbon Nanotubes and $\beta$-cyclodextrin. Sensors Actuators B: Chem. 320, 128319. doi:10.1016/j.snb.2020.128319

Arul, P., Huang, S.-T., Gowthaman, N. S. K., Mani, G., Jeromiyas, N., Shankar, S., et al. (2021). Electrocatalyst Based on Ni-MOF Intercalated with Amino AcidFunctionalized Graphene Nanoplatelets for the Determination of Endocrine Disruptor Bisphenol A. Analytica Chim. Acta 1150, 338228. doi:10.1016/j.aca. 2021.338228

Bas, S. Z., Yuncu, N., Atacan, K., and Ozmen, M. (2021). A Comparison Study of MFe2O4 (M: Ni, Cu, Zn)-Reduced Graphene Oxide Nanocomposite for Electrochemical Detection of Bisphenol A. Electrochimica Acta 386, 138519. doi:10.1016/j.electacta.2021.138519

Beduk, T., Ait Lahcen, A., Tashkandi, N., and Salama, K. N. (2020). One-step Electrosynthesized Molecularly Imprinted Polymer on Laser Scribed Graphene Bisphenol a Sensor. Sensors Actuators B: Chem. 314, 128026. doi:10.1016/j.snb. 2020.128026

Beduk, T., Beduk, D., De Oliveira Filho, J. I., Zihnioglu, F., Cicek, C., Sertoz, R., et al. (2021a). Rapid Point-of-Care COVID-19 Diagnosis with a GoldNanoarchitecture-Assisted Laser-Scribed Graphene Biosensor. Anal. Chem. 93, 8585-8594. doi:10.1021/acs.analchem.1c01444

Beduk, T., De Oliveira Filho, J. I., Ait Lahcen, A., Mani, V., and Salama, K. N. (2021b). Inherent Surface Activation of Laser-Scribed Graphene Decorated with $\mathrm{Au}$ and Ag Nanoparticles: Simultaneous Electrochemical Behavior toward Uric Acid and Dopamine. Langmuir 37, 13890-13902. doi:10.1021/acs. langmuir.1c02379

Belbruno, J. J. (2019). Molecularly Imprinted Polymers. Chem. Rev. 119, 94-119. doi:10.1021/acs.chemrev.8b00171

Ben Messaoud, N., Ait Lahcen, A., Dridi, C., and Amine, A. (2018). Ultrasound Assisted Magnetic Imprinted Polymer Combined Sensor Based on Carbon Black and Gold Nanoparticles for Selective and Sensitive Electrochemical Detection of Bisphenol A. Sensors Actuators B: Chem. 276, 304-312. doi:10. 1016/j.snb.2018.08.092

Campanale, C., Massarelli, C., Savino, I., Locaputo, V., Uricchio, V. F. J. I. J. O. E. R., and Health, P. (2020). A Detailed Review Study on Potential Effects of Microplastics and Additives of Concern on Human Health. Ijerph 17, 1212. doi:10.3390/ijerph17041212

Chen, D., Kannan, K., Tan, H., Zheng, Z., Feng, Y.-L., Wu, Y., et al. (2016). Bisphenol Analogues Other Than BPA: Environmental Occurrence, Human Exposure, and Toxicity-A Review. Environ. Sci. Technol. 50, 5438-5453. doi:10. 1021/acs.est.5b05387

Cobellis, L., Colacurci, N., Trabucco, E., Carpentiero, C., and Grumetto, L. (2009). Measurement of Bisphenol A and Bisphenol B Levels in Human Blood Sera from Healthy and Endometriotic Women. Biomed. Chromatogr. 23, 1186-1190. doi:10.1002/bmc.1241

Fenzl, C., Nayak, P., Hirsch, T., Wolfbeis, O. S., Alshareef, H. N., and Baeumner, A. J. (2017). Laser-Scribed Graphene Electrodes for Aptamer-Based Biosensing. ACS Sens. 2, 616-620. doi:10.1021/acssensors.7b00066

García-Córcoles, M., Cipa, M., Rodríguez-Gómez, R., Rivas, A., Olea-Serrano, F., Vílchez, J., et al. (2018). Determination of Bisphenols with Estrogenic Activity in Plastic Packaged Baby Food Samples Using Solid-Liquid Extraction and Clean-Up with Dispersive Sorbents Followed by Gas Chromatography Tandem Mass Spectrometry Analysis. Talanta 178, 441-448. doi:10.1016/j.talanta.2017. 09.067
Ghanam, A., Lahcen, A. A., and Amine, A. (2017). Electroanalytical Determination of Bisphenol A: Investigation of Electrode Surface Fouling Using Various Carbon Materials. J. Electroanalytical Chem. 789, 58-66. doi:10.1016/j. jelechem.2017.02.026

Ghanam, A., Lahcen, A. A., Beduk, T., Alshareef, H. N., Amine, A., and Salama, K. N. (2020). Laser Scribed Graphene: A Novel Platform for Highly Sensitive Detection of Electroactive Biomolecules. Biosens. Bioelectron. 168, 112509. doi:10.1016/j.bios.2020.112509

Govindasamy, M., Manavalan, S., Chen, S.-M., Rajaji, U., Chen, T.-W., Al-Hemaid, F. M. A., et al. (2018). Determination of Neurotransmitter in Biological and Drug Samples Using Gold Nanorods Decoratedf-MWCNTs Modified Electrode. J. Electrochem. Soc. 165, B370-B377. doi:10.1149/2.1351809jes

Grumetto, L., Montesano, D., Seccia, S., Albrizio, S., Barbato, F., and Chemistry, F. (2008). Determination of Bisphenol A and Bisphenol B Residues in Canned Peeled Tomatoes by Reversed-phase Liquid Chromatography. J. Agric. Food Chem. 56, 10633-10637. doi:10.1021/jf802297z

Huang, Y. Q., Wong, C. K. C., Zheng, J. S., Bouwman, H., Barra, R., Wahlström, B., et al. (2012). Bisphenol A (BPA) in China: A Review of Sources, Environmental Levels, and Potential Human Health Impacts. Environ. Int. 42, 91-99. doi:10. 1016/j.envint.2011.04.010

Im, J., Löffler, F. E., and Technology (2016). Fate of Bisphenol A in Terrestrial and Aquatic Environments. Environ. Sci. Technol. 50, 8403-8416. doi:10.1021/acs. est.6b00877

Karthika, P., Shanmuganathan, S., Viswanathan, S., and Delerue-Matos, C. (2021). Molecularly Imprinted Polymer-Based Electrochemical Sensor for the Determination of Endocrine Disruptor Bisphenol-A in Bovine Milk. Food Chem. 363, 130287. doi:10.1016/j.foodchem.2021.130287

Krishnamurthy, S., Esterle, A., Sharma, N. C., and Sahi, S. V. (2014). Yucca-derived Synthesis of Gold Nanomaterial and Their Catalytic Potential. Nanoscale Res Lett. 9, 627. doi:10.1186/1556-276x-9-627

Lahcen, A. A., and Amine, A. (2019). Recent Advances in Electrochemical Sensors Based on Molecularly Imprinted Polymers and Nanomaterials. Electroanalysis 31, 188-201. doi:10.1002/elan.201800623

Lahcen, A. A., Baleg, A. A., Baker, P., Iwuoha, E., and Amine, A. (2017). Synthesis and Electrochemical Characterization of Nanostructured Magnetic Molecularly Imprinted Polymers for 17- $\beta$-Estradiol Determination. Sensors Actuators B: Chem. 241, 698-705. doi:10.1016/j.snb.2016.10.132

Lahcen, A. A., Rauf, S., Aljedaibi, A., De Oliveira Filho, J. I., Beduk, T., Mani, V., et al. (2021). Laser-scribed Graphene Sensor Based on Gold Nanostructures and Molecularly Imprinted Polymers: Application for Her-2 Cancer Biomarker Detection. Sensors Actuators B: Chem. 347, 130556. doi:10.1016/j.snb.2021. 130556

Lahcen, A. A., Rauf, S., Beduk, T., Durmus, C., Aljedaibi, A., Timur, S., et al. (2020). Electrochemical Sensors and Biosensors Using Laser-Derived Graphene: A Comprehensive Review. Biosens. Bioelectron. 168, 112565. doi:10.1016/j.bios. 2020.112565

Latif, U., Qian, J., Can, S., and Dickert, F. (2014). Biomimetic Receptors for Bioanalyte Detection by Quartz Crystal Microbalances - from Molecules to Cells. Sensors 14, 23419-23438. doi:10.3390/s141223419

Lee, E.-H., Lee, S. K., Kim, M. J., and Lee, S.-W. (2019). Simple and Rapid Detection of Bisphenol A Using a Gold Nanoparticle-Based Colorimetric Aptasensor. Food Chem. 287, 205-213. doi:10.1016/j.foodchem.2019.02.079

Lin, J., Peng, Z., Liu, Y., Ruiz-Zepeda, F., Ye, R., Samuel, E. L., et al. (2014). Laserinduced Porous Graphene Films from Commercial Polymers. Nat. Commun. 5, 5714-5718. doi:10.1038/ncomms6714

Marques, A. C., Cardoso, A. R., Martins, R., Sales, M. G. F., and Fortunato, E. (2020). Laser-Induced Graphene-Based Platforms for Dual Biorecognition of Molecules. ACS Appl. Nano Mater. 3, 2795-2803. doi:10.1021/acsanm.0c00117

Miao, W., Wei, B., Yang, R., Wu, C., Lou, D., Jiang, W., et al. (2014). Highly Specific and Sensitive Detection of Bisphenol A in Water Samples Using an EnzymeLinked Immunosorbent Assay Employing a Novel Synthetic Antigen. New J. Chem. 38, 669-675. doi:10.1039/c3nj01094e

Mielke, H., and Gundert-Remy, U. (2009). Bisphenol A Levels in Blood Depend on Age and Exposure. Toxicol. Lett. 190, 32-40. doi:10.1016/j.toxlet.2009.06.861

Nehru, R., Hsu, Y.-F., Wang, S.-F., Dong, C.-D., Govindasamy, M., Habila, M. A., et al. (2021). Graphene oxide@Ce-Doped TiO2 Nanoparticles as Electrocatalyst Materials for Voltammetric Detection of Hazardous Methyl Parathion. Microchim Acta 188, 216. doi:10.1007/s00604-021-04847-5 
Pupo, M., Pisano, A., Lappano, R., Santolla, M. F., De Francesco, E. M., Abonante, S., et al. (2012). Bisphenol A Induces Gene Expression Changes and Proliferative Effects through GPER in Breast Cancer Cells and CancerAssociated Fibroblasts. Environ. Health Perspect. 120, 1177-1182. doi:10. 1289/ehp.1104526

Rajaji, U., Chinnapaiyan, S., Chen, T.-W., Chen, S.-M., Mani, G., Mani, V., et al. (2021). Rational Construction of Novel Strontium Hexaferrite Decorated Graphitic Carbon Nitrides for Highly Sensitive Detection of Neurotoxic Organophosphate Pesticide in Fruits. Electrochimica Acta 371, 137756. doi:10.1016/j.electacta.2021.137756

Rauf, S., Lahcen, A. A., Aljedaibi, A., Beduk, T., Ilton De Oliveira Filho, J., and Salama, K. N. (2021). Gold Nanostructured Laser-Scribed Graphene: A New Electrochemical Biosensing Platform for Potential point-of-care Testing of Disease Biomarkers. Biosens. Bioelectron. 180, 113116. doi:10.1016/j.bios.2021. 113116

Safe, S. H. (2000). Endocrine Disruptors and Human Health-Iis There a Problem? an Update. Environ. Health Perspect. 108, 487-493. doi:10.1289/ ehp.00108487

Santonicola, S., Ferrante, M. C., Murru, N., Gallo, P., and Mercogliano, R. (2019). Hot Topic: Bisphenol A in Cow Milk and Dietary Exposure at the Farm Level. J. Dairy Sci. 102, 1007-1013. doi:10.3168/jds.2018-15338

Saxena, A. P., Deepa, M., Joshi, A. G., Bhandari, S., Srivastava, A. K., and Interfaces (2011). Poly(3,4-ethylenedioxythiophene)-ionic Liquid Functionalized Graphene/reduced Graphene Oxide Nanostructures: Improved Conduction and Electrochromism. ACS Appl. Mater. Inter. 3, 1115-1126. doi:10.1021/ am101255a

Vasiljevic, T., and Harner, T. (2021). Bisphenol A and its Analogues in Outdoor and Indoor Air: Properties, Sources and Global Levels. Sci. Total Environ. 789, 148013. doi:10.1016/j.scitotenv.2021.148013

Vusa, C. S. R., Venkatesan, M., K, A., Berchmans, S., and Arumugam, P. (2017). Tactical Tuning of the Surface and Interfacial Properties of Graphene: A Versatile and Rational Electrochemical Approach. Sci. Rep. 7, 8354. doi:10. 1038/s41598-017-08627-1
Xu, W., Zhang, Y., Yin, X., Zhang, L., Cao, Y., Ni, X., et al. (2021). Highly Sensitive Electrochemical BPA Sensor Based on Titanium Nitride-Reduced Graphene Oxide Composite and Core-Shell Molecular Imprinting Particles. Anal. Bioanal. Chem. 413, 1081-1090. doi:10.1007/s00216-020-03069-7

Yin, W., Wu, L., Ding, F., Li, Q., Wang, P., Li, J., et al. (2018). Surface-imprinted SiO2@Ag Nanoparticles for the Selective Detection of BPA Using Surface Enhanced Raman Scattering. Sensors Actuators B: Chem. 258, 566-573. doi:10. 1016/j.snb.2017.11.141

Zhang, J., Wang, H., Xu, L., and Xu, Z. (2021). A Semi-covalent Molecularly Imprinted Fluorescent Sensor for Highly Specific Recognition and Optosensing of Bisphenol A. Anal. Methods 13, 133-140. doi:10.1039/d0ay01822h

Zheng, W., Xiong, Z., Li, H., Yu, S., Li, G., Niu, L., et al. (2018). Electrodeposited Pt@Molecularly Imprinted Polymer Core-Shell Nanostructure: Enhanced Sensing Platform for Sensitive and Selective Detection of Bisphenol A. Sensors Actuators B: Chem. 272, 655-661. doi:10.1016/j.snb.2018.07.039

Conflict of Interest: The authors declare that the research was conducted in the absence of any commercial or financial relationships that could be construed as a potential conflict of interest.

Publisher's Note: All claims expressed in this article are solely those of the authors and do not necessarily represent those of their affiliated organizations, or those of the 1publisher, the editors, and the reviewers. Any product that may be evaluated in this article, or claim that may be made by its manufacturer, is not guaranteed or endorsed by the publisher.

Copyright (C) 2022 Beduk, Gomes, De Oliveira Filho, Shetty, Khushaim, GarciaRamirez, Durmus, Ait Lahcen and Salama. This is an open-access article distributed under the terms of the Creative Commons Attribution License (CC BY). The use, distribution or reproduction in other forums is permitted, provided the original author(s) and the copyright owner(s) are credited and that the original publication in this journal is cited, in accordance with accepted academic practice. No use, distribution or reproduction is permitted which does not comply with these terms. 